${ }^{1}$ Center for Natural History, Universität Hamburg, Hamburg Germany; ${ }^{2}$ Naturhistorisches Museum der Burgergemeinde Bern, Bern Switzerland; ${ }^{3}$ Institute of Biodiversity and Environmental Conservation, Universiti Malaysia Sarawak, Kota Samarahan Sarawak, Malaysia

\title{
The anatomy and structural connectivity of the abdominal sucker in the tadpoles of Huia cavitympanum, with comparisons to Meristogenys jerboa (Lissamphibia: Anura: Ranidae)
}

\author{
Li Lin Gan ${ }^{1}$, Stefan T. Hertwig ${ }^{2}$, Indraneil Das ${ }^{3}$ and Alexander Haas ${ }^{1}$
}

\begin{abstract}
The tadpoles of many anuran amphibians inhabit lotic habitats and evolved oral devices to adhere to the substratum. Although published anatomical descriptions of rheophilous tadpoles exist, little is known about the modifications in gastromyzophorous tadpoles that possess abdominal suckers and live in torrential sections of streams. We describe the gastromyzophorous tadpoles of Huia cavitympanum and Meristogenys jerboa from torrential streams of Borneo, with special attention to the anatomy of their abdominal suckers and their relations to cranial structures and musculature. One cranium of $H$. cavitympanum and its associated muscles were computer-reconstructed in three dimensions from serial histological sections. The abdominal sucker and oral sucker comprise a set of muscles and ligaments that attach to internal skeletal structures. Some muscles could be identified to attach directly to soft tissue of the abdominal sucker and most likely contribute to suction. Comparing tadpoles of $H$. cavitympanum to the closely related gastromyzophorous $M$. jerboa reveals differences in external and internal features, such as cornu trabeculae fusion and jaw details. Because of phylogenetic uncertainties, it is unclear whether or not this structural complex evolved once or several times convergently in ranids.
\end{abstract}

Key words: Anura - Lissamphibia - larval cranium - gastromyzophorous - rheophilous - three-dimensional

\section{Introduction}

Altig and Johnston (1989) defined seven ecomorphological guilds of tadpoles that occur only in lotic aquatic environments: the adherent, clasping, fossorial, gastromyzophorous, psammonic, suctorial and semi-terrestrial guilds of tadpoles. Of these, three types of tadpoles are known to live in the current (McDiarmid and Altig 1999): adherent/clasping tadpoles live in slow-flowing sections of streams. They possess ventrals oral discs (for example, Ansonia leptopus [Günther, 1872]; personal observation AH). Lotic, suctorial tadpoles possess an enlarged oral disc that forms an oral sucker apparatus (for example, Ansonia hanitschi Inger, 1960; Ascaphus truei Stejneger, 1899; and some Litoria species; Haas and Richards 1998; Haas et al. 2009). Gastromyzophorous tadpoles bear a well-developed abdominal sucker located posterior to the oral sucker that enables these tadpoles to adhere tightly to rocks in strong current or torrential stream sections. Gastromyzophorous larvae have been described in the Ranidae (Amolops; Huia; Meristogenys; Rana sauteri Boulenger, 1909; Annandale and Hora 1922; Hora 1930; Inger 1966; Kuramoto et al. 1984; Yang 1991; Chou and Lin 1997; Malkmus et al. 2002; Matsui et al. 2006; Ngo et al. 2006; Shimada et al. 2007 a,b; Stuart 2008) and the Bufonidae (Atelopus, possibly Sabahphrynus maculatus (Mocquard, 1890), and some Rhinella; Starrett 1967; Duellman and Lynch 1969; Mebs 1980; Lescure 1981; Gray and Cannatella 1985; Lynch 1986; Lindquist and Hetherington 1988; Gascon 1989; McCranie et al. 1989; Cadle and Altig 1991; Inger 1992; Rao and Yang 1994; Lavilla et al. 1997; Matsui et al. 2007; Aguayo et al. 2009; Rueda-Solano et al. 2015). Semiterrestrial tadpoles with expanded abdominal skin (Thoropa petropolitana (Wandolleck, 1907); Cycloramphus valae Heyer, 1983; Lavilla 1988) are not considered gastromy-

Corresponding author: Alexander Haas (alexander.haas@uni-hamburg. de)

Contributing authors: Li Lin Gan (lgan@dpz.eu), Stefan T. Hertwig (stefan.hertwig@nmbe.ch), Indraneil Das (idas@ibec.unimas.my), Alexander Haas (alexander.haas@uni-hamburg.de) zophorous herein. Some accounts have been published on the muscles and ligaments that insert to the abdominal suckers in gastromyzophorous larvae (Annandale and Hora 1922; Noble 1929; Kaplan 1997; Aguayo et al. 2009).

The term 'gastromyzophorous' tadpoles was first used by Inger (1966), who described tadpoles from Borneo that inhabit fast flowing, turbulent waters and that have specific morphological characteristics, that is, a well-developed abdominal sucker, expanded oral disc, low caudal fins and massive caudal muscles, correlated to the living in strong current (Altig and Johnston 1989; Altig and McDiarmid 1999; McDiarmid and Altig 1999; Lavilla and de Sá 2001). Large abdominal suckers have been interpreted as an adaptation to high water velocity (Boistel et al. 2005). Although various taxa have conquered high velocity microhabitats successfully with an oral sucker only, among the Bornean fauna, gastromyzophorous larvae of Huia cavitympanum (Boulenger, 1893) and Meristogenys species have been particularly successful in using very high velocity currents as microhabitat (Inger 1985; Shimada et al. 2007a,b).

The tadpoles of Huia cavitympanum are of interest because of their remarkable ability to withstand strong currents and for phylogenetic reasons. The hypothesized phylogeny of Huia has undergone several changes and remains controversial (Stuart 2008). Inger (1966) united Asian ranid species with well-developed abdominal suckers into the genus Amolops. Subsequently, Yang (1991) recovered three groups within Amolops. In his phylogenetic analysis of morphological characters, they were assigned to the genera Amolops, Meristogenys and Huia, respectively. The genus Meristogenys was defined by synapomorphy in that analysis: larval upper beak divided and ribbed on its outer surface. Yang (1991) defined the genus Huia with one synapomorphy: larvae with scattered glands on the back. Some Huia species possess scattered dorsal glands, yet this character is absent in the type species, H. cavitympanum (Inger 1985; Stuart 2008). Stuart (2008) and Wiens et al. (2009) suggested Huia to be paraphyletic and the type species $H$. cavitympanum to be the sister taxon to the genus Meristogenys. They further argued that the remaining species, which Yang (1991) allocated to 'Huia', 